\title{
Statin Reduces C-Reactive Protein and Interleukin-6 in Normocholesterolemic Patients with Acute Coronary Syndrome
}

\author{
Ok Young Park, Soo Hang Kim, Young Keun Ahn ${ }^{1 *}$, Nam Sik Yun ${ }^{1}$, Ju Han Kim, \\ Du Sun Sim${ }^{1}$, Hyun Ju Yoon ${ }^{1}$, Kye Hun Kim¹, Hyung Wook Park', \\ Young Joon Hong ${ }^{1}$, Myung Ho Jeong ${ }^{1}$, Jeong Gwan $\mathrm{Cho}^{1}$ and Jong Chun Park ${ }^{1}$ \\ Department of Internal Medicine, College of Medicine Seonam University, Namwon, \\ ${ }^{1}$ Department of Cardiovascular Medicine, The Heart Center of Chonnam National University Hospital, \\ Cardiovascular Research Institute of Chonnam National University, Gwangiu, Korea
}

\begin{abstract}
Many evidences suggest that atherosclerosis is an inflammatory disease and inflammatory markers can be an important prognostic factors in acute coronary syndrome. Hydroxymethylglutaryl (HMG-CoA) reductase inhibitors (statins) have been shown anti-inflammatory property that are independent of lipid-lowering effects. We evaluated the effects of 2-month treatment with simvastatin $(40 \mathrm{mg} / \mathrm{d}, \mathrm{n}=20)$ on plasma levels of circulating high-sensitivity C-reactive protein (hsCRP), inflammatory cytokines [tumor necrosis factor (TNF)- $\alpha$, interleukin (IL)-1 $\beta$, IL-6], and adhesion molecules [p-selectin and monocyte chemotactic peptide (MCP)-1] with placebo group $(n=20)$ in 40 normocholesterolemic patients $(L D L<130 \mathrm{mg} / \mathrm{dl})$ with acute coronary syndrome. Simvastatin therapy significantly reduced plasma levels of total cholesterol and LDL-cholesterol $(p=0.05, p=0.02$, respectively) compared with placebo group. Simvastatin therapy also significantly reduced plasma levels of hsCRP and IL-6 $(p=0.03, p=0.03$, respectively) compared with placebo group. But, the reduction of hsCRP and IL-6 levels with simvastatin was unrelated to the degree of LDL-cholesterol's reduction. The effect of simvastatin on the reduction of hSCRP and IL-6, but not on the other inflammatory cytokines and adhesion molecules, have potential implications in the management of acute coronary syndrome with normocholesterolemia.
\end{abstract}

Keywords: CRP protein; Hydroxymethylglutaryl-CoA Reductase Inhibitors; Cholesterol

\section{Introduction}

Many lines of evidence suggest that atherosclerosis is an inflammatory disease and biomarkers of inflammation could be an important prognostic factors in acute coronary syndrome. ${ }^{1-9}$ Statins are main drugs to reduce plasma levels of total cholesterol and LDL-cholesterol

Accepted for Publication: March 19, 2008

*Corresponding author: Youngkeun Ahn, 590-711, Department of Cardiovascular Medicine, The Heart Center of Chonnam National University Hospital, Phone: 062-220-4764, FAX: 062-227-7174, E-mail: cecilyk@ chonnam.ac.kr and confirm clinical benefits from primary and secondary prevention trials. ${ }^{10-12}$ Recently, these agent have been shown to reduce atherosclerotic cardiovascular mortality and morbidity via pleiotropic effects including an anti-inflammatory, anti-thrombotic, and anti-oxidant action that are independent of lipid-lowering effects in hypercholesterolemic patients. ${ }^{13-15}$ But, little has been known that the effect of statin on systemic inflammation with subsequent left ventricular function in normocholesterolemic patients with acute ccoronary syndrome.

This study was designed to document the effect of statin on the variety of inflammatory markers and left 
ventircular remodeling in normocholesterolemic patients with acute coronary syndrome.

\section{Materials and Methods}

The treatment plan and investigations were designed in accordance with the guidelines of the local ethical committee (Chonnam National University Hospital). We evaluated the effect of 2-month treatment with simvastatin [Zocor ${ }^{\mathbb{R}} 40 \mathrm{mg}$-Group II $(\mathrm{n}=20)$ ] on plasma levels of circulating hsCRP, inflammatory cytokines (TNF- $\alpha$, IL-1 $\beta$, IL-6), and adhesion molecules (pselectin and MCP-1) with placebo group (Group I $(\mathrm{n}=20)]$ in 40 normocholesterolemic patients (LDL $<130 \mathrm{mg} / \mathrm{dl}$ ) with unstable angina and acute myocardial infarction. Blood was taken from all patients at the first day of treatment (before the drug intake) and after 2 months of treatment. Serum was collected using pyrogen-free tubes without additives. Immediately after blood collection, the tubes were immersed into melting ice and allowed to clot for 30 min before centrifugation at $1,500 \mathrm{~g}$ for 5 minutes. Serum samples were stored at $-80^{\circ} \mathrm{C}$ in multiple aliquots until analysis. Samples were thawed only once. Cholesterol and triglyceride concentrations were determined with commercially available enzymatic methods. High-sensitivity C-reactive protein (hsCRP) was measured by the latex photometric immunoassay method. Serum levels of tumor necrosis factor (TNF)- $\alpha$, interleukin (IL)-1 $\beta$, IL-6, p-selectin, and monocyte chemotactic peptide (MCP)-1 were determined by a commercially available assay (Quantikine TNF- $\alpha$, IL-1 $\beta$, IL-6 MCP-1, Parameter p-selectin, $\mathrm{R} \& \mathrm{D}$ Systems) at Green Cross Reference Laboratory. Analysis was performed in duplicates in a blinded fashion. All samples from a given patient were analyzed in the same microtiter plate to minimize run-to-run variability. All patients gave informed consent before blood donation. Previous medication did not change during statin treatment. No other lipid-lowering drugs were applied throughout the observation period.
Transthoracic echocardiogram was performed before and 2 months after treatment with simvastatin or placebo. And left ventricular (LV) end-diastolic and end-systolic dimension, LV mass, LV volumes, and LV ejection fraction were determined.

\section{Statistics}

For the statistical analysis, the unpaired t-test and Chi-square test were performed using SPSS-PC 11.0 (Statistical package for the social sciences, SPSS-PC Inc. Chicago, IL, USA) and the values were designed as mean \pm standard error. A value of $\mathrm{P}$ less than 0.05 was considered as significant.

\section{Results}

The baseline characteristics of the study population are given in Table 1. No significant differences were observed between the groups.

Simvastatin therapy significantly reduced total plasma cholesterol $(168.3 \pm 5.9$ to $134.3 \pm 7.0 \mathrm{mg} / \mathrm{dl})$ and LDLcholesterol $(112.8 \pm 4.4$ to $82.1 \pm 5.0 \mathrm{mg} / \mathrm{dl})$ concentrations when compared with placebo group $(p=0.05, p=$ 0.02 , respectively). Whereas changes in the concentrations of triglyceride-rich particles and HDL-cholesterol

Table 1. Baseline clinical characteristics

\begin{tabular}{lccc}
\hline & Group I (n=20) & Group II (n=20) & p-value \\
\hline Age (year) & $59 \pm 5$ & $62 \pm 5$ & 0.634 \\
Male (\%) & $17(85)$ & $16(80)$ & 0.778 \\
Hypertension (\%) & $17(85)$ & $16(80)$ & 0.778 \\
Diabetes mellitus (\%) & $14(70)$ & $18(90)$ & 0.354 \\
Smoking (\%) & $14(70)$ & $14(70)$ & 0.953 \\
Troponin-I (ng/ml) & $3.2 \pm 4.0$ & $7.0 \pm 0.4$ & 0.225 \\
ESR (mg/dl) & $4.8 \pm 2.4$ & $33.4 \pm 9.4$ & 0.180 \\
PCI (\%) & $18(90)$ & $18(90)$ & 0.834 \\
Unstable angina (\%) & $3(15)$ & $2(10)$ & 0.803 \\
Acute MI (\%) & $17(85)$ & $18(90)$ & 0.803 \\
Beta blocker (\%) & $18(90)$ & $17(85)$ & 0.803 \\
ACEl or ARB (\%) & $15(75)$ & $16(80)$ & 0.704 \\
\hline
\end{tabular}

$\mathrm{MI}$, myocardial infarction, ACEl: angiotensin converting enzyme inhibitor; ARB: Angiotensin receptor blocker, PCl: percutaneous coronary intervention 
Table 2. Plasma levels of lipid profiles before and 2 months of placebo and simvastatin treatment

\begin{tabular}{lccccc}
\hline & \multicolumn{2}{c}{ Group I $(\mathrm{n}=20)$} & & \multicolumn{2}{c}{ Group $\|(\mathrm{n}=20)$} \\
\cline { 2 - 3 } \cline { 5 - 6 } & Before & 2 months & & Before & 2 months \\
\hline T-chol $(\mathrm{mg} / \mathrm{dl})^{*}$ & $163.3 \pm 9.8$ & $169.4 \pm 17.5$ & & $168.3 \pm 5.9$ & $134.3 \pm 7.0$ \\
$\mathrm{LDL}$-chol $(\mathrm{mg} / \mathrm{d})^{*}$ & $104.4 \pm 7.7$ & $114.1 \pm 15.7$ & & $112.8 \pm 4.4$ & $82.1 \pm 5.0$ \\
$\mathrm{HDL}-\mathrm{chol}(\mathrm{mg} / \mathrm{dll})$ & $48.9 \pm 4.5$ & $42.3 \pm 3.7$ & & $39.5 \pm 3.7$ & $41.3 \pm 4.7$ \\
$\mathrm{TG}(\mathrm{mg} / \mathrm{dll})$ & $109.1 \pm 20.3$ & $152.6 \pm 26.7$ & & $103.2 \pm 13.4$ & $126.0 \pm 14.4$ \\
\hline
\end{tabular}

T-chol, total cholesterol; LDL-chol: low density lipoprotein-cholesterol; HDL-chol, high density lipoprotein-cholesterol; TG, triglyceride. ${ }^{*} p<0.05$, Changes $(\Delta)$ in the profiles after 2 months of simvastatin treatment vs. placebo

Table 3. Plasma levels of inflammatory markers before and 2 months of placebo and simvastatin treatment

\begin{tabular}{|c|c|c|c|c|}
\hline & \multicolumn{2}{|c|}{ Group I $(n=20)$} & \multicolumn{2}{|c|}{ Group $\|(n=20)$} \\
\hline & Before & 2 months & Before & 2 months \\
\hline hsCRP $(\mathrm{mg} / \mathrm{dl})^{\star}$ & $2.82 \pm 1.73$ & $0.86 \pm 0.98$ & $3.51 \pm 3.43$ & $0.27 \pm 0.43$ \\
\hline TNF- $\alpha \quad(\mathrm{pg} / \mathrm{ml})$ & $1.59 \pm 0.23$ & $2.85 \pm 1.26$ & $1.71 \pm 0.39$ & $2.21 \pm 0.41$ \\
\hline$\| \mathrm{L}-1 \beta \quad(\mathrm{pg} / \mathrm{ml})$ & $0.37 \pm 0.12$ & $1.07 \pm 0.78$ & $0.63 \pm 0.21$ & $0.37 \pm 0.14$ \\
\hline IL-6 (pg/ml) $)^{*}$ & $5.78 \pm 3.66$ & $2.21 \pm 1.35$ & $8.06 \pm 4.78$ & $1.81 \pm 0.79$ \\
\hline P-selectin (ng/ml) & $62.9 \pm 12.2$ & $60.1 \pm 11.2$ & $51.4 \pm 10.6$ & $43.1 \pm 7.8$ \\
\hline MCP-1 (pg/ml) & $237.1 \pm 39.3$ & $157.2 \pm 25.6$ & $261.1 \pm 24.5$ & $179.0 \pm 32.9$ \\
\hline
\end{tabular}

hsCRP, High-sensitivity C-reactive protein; TNF- $\alpha$, tumor necrosis factor- $\alpha$; IL-1 $\beta$, interleukin $-1 \beta$; IL-6, interleukin-6; MCP-1, monocyte chemotactic peptide $-1 .{ }^{*} p<0.05$, Changes $(\Delta)$ in the profiles after 2 months of simvastatin treatment vs. placebo

were less pronounced (Table 2).

Simvastatin therapy significantly reduced the hsCRP $(3.51 \pm 3.43$ to $0.27 \pm 0.43 \mathrm{mg} / \mathrm{dl})$ and IL-6 $(8.06 \pm 4.78$ to $1.81 \pm 0.79 \mathrm{pg} / \mathrm{mL}$ ) levels when compared with placebo group ( $\mathrm{p}=0.03, \mathrm{p}=0.03$, respectively) (Table 3 ). The reductions of hsCRP and IL-6 levels with simvastatin were unrelated to the degree of LDL-cholesterol reduction $(r=0.195,0.210, p=0.470,0.436$, respectively). However, simvastatin did not significantly decrease other inflammatory cytokines and adhesion molecules when compared with placebo group (Table 3). The LV endsystolic and end-diastolic dimensions, LV mass, and LV ejection fraction were not changed significantly after simvastatin treatment when compared with placebo group (Fig. 1).

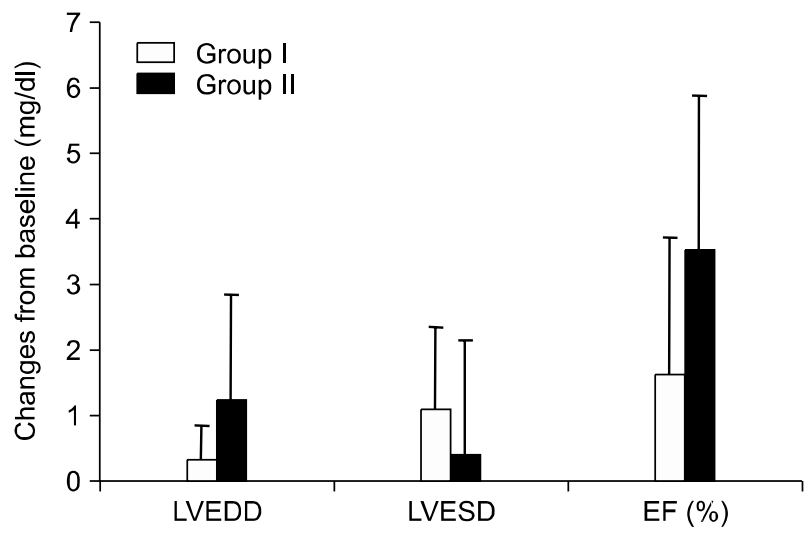

Fig. 1. Changes in LVEDd and LVESd, and LV ejection fraction (EF) after 2 months of placebo and simvastatin treatment. LVEDd, left ventricular (LV) end-diastolic dimension; LVESd, LV end systolic dimension (LVESd); EF, LV ejection fraction.

\section{Discussion}

Our understanding of the mechanisms underlying atherogenesis and its sequelae, such as unstable angina and acute myocardial infarction, have evolved and changed. Many reports suggest that inflammation plays a role in both the initial formation of atherosclerotic plaque and the rupture of these plaques underlying acute clinical presentations are closely tied to inflammatory activation of cells both in the vessel wall and circulating in the blood stream. ${ }^{1-3}$ Systemic markers of inflammation, such as white blood cells, C-reactive protein, serum amyloid A, interleukin-6, and soluble adhesion molecules are predictive of future cardiovascular events. $^{4-7}$

Aggressive statin therapy have reduced the hsCRP levels in the patients with hypercholesterolemia and extent of hs-CRP reduction is associated with the progression rate of the atherosclerotic process. ${ }^{16} \mathrm{Li}$ et al. ${ }^{17}$ demonstrated that CRP could induce IL-6 release in human monocytes and simvastatin could inhibit this response in a dose-dependent manner. Some animal experiments reported that statin therapy profoundly changed the LV remodeling after myocardial infarction. ${ }^{18,19}$

This study demonstrated that 2-months simvastatin treatment decreased hsCRP and IL-6 in normocholesterolemic patients with acute coronary syndrome. For 
the elucidation of pleotropic effects by statin such as anti-inflammation, 2-months interval is sufficient. Simvastatin therapy did not change significantly LV remodeling in short period even though the LV end-diastolic dimension inclined to decrease with simvastatin treatment. Long-term follow-up of the effect of statin on the LV remodeling has to be determined.

In summary, this study showed simvastatin reduced hsCRP and IL-6 levels in normocholesterolemic patients with acute coronary syndrome. The effect of simvastatin on hsCRP and IL-6 levels was independent of lipid lowering efficacy.

\section{References}

1. Ross R. Atherosclerosis--an inflammatory disease. N Engl J Med 1999; 340:115-26.

2. Shah PK. Plaque disruption and thrombosis: potential role of inflammation and infection. Cardiol Rev 2000;8:31-9.

3. Buffon A, Biasucci LM, Liuzzo G, D’Onofrio G, Crea F, Maseri A. Widespread coronary inflammation in unstable angina. $N$ Engl $J$ Med 2002;347:5-12.

4. Rosenson RS, Koenig W. Utility of inflammatory markers in the management of coronary artery disease. Am J Cardiol 2003;92:10i-8i.

5. März W, Köenig W. HMG-CoA reductase inhibition: anti-inflammatory effects beyond lipid lowering? J Cardiovasc Risk 2003;10:169-79.

6. Blake GJ, Ridker PM. Novel clinical markers of vascular wall inflammation. Circ Res 2001;89:763-71.

7. Shah SH, Newby LK. C-reactive protein: a novel marker of cardiovascular risk. Cardiol Rev 2003;11:169-79.

8. Kim KH, Jeong MH, Shin JH, Joo SB, Kim W, Lee SU, et al. The role of chronic infection and inflammation in Korean patients with coronary artery disease. Korean Circ J 2000;30:1107-16.
9. Hong YJ, Jeong MH, Park HW, Lee SH, Park OK, Jeong WK, et al. The role of C-reactive protein on long-term clinical outcomes in patients with acute myocardial infarction. Korean J Med 2001;61:60616.

10. Randomized trial of cholesterol lowering in 4444 patients with coronary heart disease: the Scandinavian Simvastatin Survival Study (4S). Lancet 1994;344:1383-9.

11. Heart Protection Study Collaborative Group. MRC/BHF Heart Protection Study of cholesterol lowering with simvastatin in 20,536 high-risk individuals: a randomised placebo- controlled trial. Lancet 2002;360:7-22.

12. Law MR, Wald NJ, Rudnicka AR. Quantifying effect of statins on low density lipoprotein cholesterol, ischaemic heart disease, and stroke: systematic review and meta-analysis. BMJ 2003;326:1423.

13. Shishehbor MH, Brennan ML, Aviles RJ, Fu X, Penn MS, Sprecher $\mathrm{DL}$, et al. Statins promote potent systemic antioxidant effects through specific inflammatory pathways. Circulation 2003;108:426-31.

14. McKeown B, Thompson PL. Early initiation of statin therapy after a coronary event. Curr Opin Lipidol 2002;13:631-5.

15. Kanadasi M, Cayli M, Demirtas M, Inal T, Demir M, Koc M, et al. The effect of early statin treatment on inflammation and cardiac events in acute coronary syndrome patients with low-density lipoprotein cholesterol. Heart Vessels 2006;21:291-7.

16. van Wissen S, Trip MD, Smilde TJ, de Graaf J, Stalenhoef AF, Kastelein JJ. Differential hs-CRP reduction in patients with familial hypercholesterolemia treated with aggressive or conventional statin therapy. Atherosclerosis 2002;165:361-6.

17. Li JJ, Chen XJ. Simvastatin inhibits interleukin-6 release in human monocytes stimulated by C-reactive protein and lipopolysaccharide. Coron Artery Dis 2003;14:329-34.

18. Nahrendorf M, Hu K, Hiller KH, Galuppo P, Fraccarollo D, Schweizer $\mathrm{G}$, et al. Impact of hydroxymethylglutaryl coenzyme a reductase inhibition on left ventricular remodeling after myocardial infarction: an experimental serial cardiac magnetic resonance imaging study. $J \mathrm{Am}$ Coll Cardiol 2002;40:1695-700.

19. Bauersachs J, Galuppo P, Fraccarollo D, Christ M, Ertl G. Improvement of left ventricular remodeling and function by hydroxymethylglutaryl coenzyme a reductase inhibition with cerivastatin in rats with heart failure after myocardial infarction. Circulation 2001;104:982-5. 